\section{Social defeat: risk factor for schizophrenia?}

\author{
JEAN-PAUL SELTEN and ELIZABETH CANTOR-GRAAE
}

\begin{abstract}
Summary The hypothesis that chronic and long-term experience of 'social defeat' may increase the risk for schizophrenia is proposed. This increased risk may result from sensitisation of the mesolimbic dopamine system and/or increased baseline activity of this system. Data supporting the social defeat hypothesis are presented.
\end{abstract}

\section{Declaration of interest None.}

This editorial proposes the hypothesis that a chronic and long-term experience of social defeat may lead to sensitisation of the mesolimbic dopamine system (and/or to increased baseline activity of this system) and thereby increase the risk for schizophrenia. The currently dominant belief that 'psychosocial stress' plays only a modest role in the aetiology of schizophrenia has become untenable in the light of new epidemiological findings, especially those concerning migrants.

\section{RISK FACTORS FOR SCHIZOPHRENIA}

Some important risk factors for schizophrenia, other than purely genetic factors, are urban upbringing, migration, low IQ and the use of illicit drugs. Studies in Europe have shown that people raised in urban areas have a 1.5-3 times higher risk of developing schizophrenia (Pedersen \& Mortensen, 2001). Accumulating evidence indicates that migrants are also at increased risk. A recent meta-analysis of incidence studies in migrants demonstrated that the mean weighted relative risk (RR) for firstand second-generation migrants was 2.9 (95\% CI 2.5-3.4) (Cantor-Graae \& Selten, 2005). Subgroup comparisons yielded significantly greater effect sizes for migrants from areas where the majority of the population is Black $(\mathrm{RR}=4.8,95 \% \mathrm{CI}$
3.7-6.2). The broad spectrum of the countries of origin and the increased risks for first- and second-generation migrants suggest that a single genetic or biological factor cannot explain these findings. The greater effect size associated with Black skin colour suggests a role for psychosocial adversity.

Another risk factor is low IQ. A followup study of Swedish recruits showed that risk for schizophrenia was linearly related to low IQ. For example, the risk for people with an IQ of 82-95 was 3.5 times higher than the risk for those with an IQ > 126 (David et al, 1997). Finally, the use of cannabis and other dopamineenhancing drugs approximately doubles an individual's risk of later schizophrenia (Arseneault et al, 2004).

\section{SOCIAL DEFEAT \\ AS A UNIFYING MECHANISM}

Is it possible to find a common mechanism for these intriguing findings? Since both migrants and city residents are exposed to high levels of social competition, the longterm experience of social defeat, defined as a subordinate position or as 'outsider status', is a viable candidate. This is compatible with the recent meta-analysis of studies on migrants, which showed greater effect sizes for migrants from developing countries than for those from developed countries, and greater effect sizes for the second generation than for the first. A bigger increase in the second generation is expected, because outsider status would be even more humiliating for individuals who feel entitled to the status conferred by their birthright. Since discrimination would certainly contribute to the migrant's experience of defeat, it is noteworthy that a prospective study in The Netherlands found that perceived discrimination was a risk factor for the development of psychotic symptoms (Janssen et al, 2003). The risks for immigrant groups known for their strong family networks, for example Asian immigrants to the UK and Turkish immigrants to The Netherlands, are not nearly as high as those for Caribbean immigrants to the UK or Moroccan immigrants to The Netherlands. Moreover, the incidence in minority ethnic groups is smaller when they comprise a greater proportion of the local population (Boydell et al, 2001). A plausible interpretation of these findings is that social support protects against the development of schizophrenia and this accords well with the social defeat hypothesis.

The hypothesis also accords with the findings on IQ, because low IQ puts people at a social disadvantage. However, alternative interpretations are possible as low IQ may primarily reflect a disturbance in cerebral development. Finally, social defeat may lead to more frequent use of illicit drugs and to a greater susceptibility to these substances (see below). It is important to note that social defeat is not always followed by the development of a psychiatric disorder, and that it is also a risk factor for depression and addiction. Other factors, including genetic vulnerability, would determine the nature of the outcome. However, since genetic vulnerability to schizophrenia may be present in $10-20 \%$ of the population, the experience of defeat may strongly influence the development of the schizophrenia phenotype. The absence of a strong association between low socio-economic status of the parents and risk for schizophrenia in the offspring does not necessarily argue against the hypothesis, because the experience of defeat depends primarily on interpretation. Thus, the extent to which exposure to social adversity leads to social defeat may vary. Defeat may be more frequent in immigrants whose notions concerning the ease of upward mobility are thwarted by the opportunities currently available in Western society.

\section{BIOLOGICAL ASPECTS OF THE SOCIAL DEFEAT HYPOTHESIS}

Evidence for the role of dopamine in the development of schizophrenia is provided by the increased occupancy of striatal $\mathrm{D}_{2}$ receptors by dopamine in untreated patients, the psychotogenic effects of dopamine-enhancing drugs and the known 
mode of action of antipsychotic drugs (blockade of $\mathrm{D}_{2}$ receptors; reviewed by Laruelle, 2003). Furthermore, current evidence indicates that the mesolimbic dopamine system is sensitised in schizophrenia. Sensitisation is a process whereby exposure to a given stimulus results in an enhanced response at subsequent exposures, in this example excess release of dopamine or the development of psychotic symptoms. There are two arguments for this. First, neuroreceptor imaging studies have shown that amphetamine-induced dopamine release is increased in schizophrenia. Second, many patients display increased sensitivity to the psychotogenic effects of illicit drugs. This means that they develop psychotic symptoms after exposure to doses that do not induce psychosis in healthy individuals (Laruelle, 2003). However, dopamine only mediates psychosis. Thus, important questions remain concerning the nature of the earlier events that lead to dopaminergic dysregulation. A series of animal experiments suggest that social defeat could well be one of these earlier events. An animal model for social defeat stress is the 'resident-intruder' paradigm, whereby a male rodent (the intruder) is put into the cage of another male (the resident). Within a minute the resident attacks the intruder and prompts him to display submissive behaviour. This experiment showed that social defeat stress leads to dopaminergic hyperactivity in the mesocorticolimbic system, not in the nigrostriatal system (Tidey \& Miczek, 1996). The effects depended on the housing conditions after defeat. Lengthy isolation after defeat amplified the changes in dopaminergic activity, whereas return to the group mitigated the changes (Isovich $e t$ al, 2001). (The reader may note a parallel with the effects of social cohesion and high ethnic density.) The researchers also found that repeated experiences of defeat lead to behavioural sensitisation, in which the animal displays an enhanced behavioural response to dopamine agonists (Covington $\&$ Miczek, 2001). If the results of animal experiments can be extended to humans, chronic exposure to social defeat may lead to sensitisation of the mesolimbic dopamine system and/or overactivity of this system, and thus further the development of psychosis. These developments would also be facilitated by the use of

JEAN-PAUL SELTEN, MD PhD, Department of Psychiatry, Rudolf Magnus Institute of Neuroscience, University Medical Centre Utrecht, Utrecht, The Netherlands, ELIZABETH CANTOR-GRAAE, PhD, Department of Community Medicine, Lund University, University Hospital UMAS, Malmö, Sweden

Correspondence: Dr J. P. Selten, Department of Psychiatry, University Hospital, PO Box 85500, 3508 GA Utrecht, The Netherlands. Tel: +3I 30 2508180; fax: +3l 30 2505443; e-mail: j.p.selten@azu.nl

(First received 16 June 2004, final revision 30 March 2005, accepted 3 May 2005)

dopamine-enhancing drugs (such as cannabis).

\section{HOW TO TEST THE HYPOTHESIS?}

It is unethical to subject humans to a randomised experiment in which chronic defeat is the exposure condition and schizophrenia the possible outcome. Animals can be subjected to such experiments but they will not develop schizophrenia. Furthermore, the experience of social defeat is difficult to measure because individual self-assessments are sensitive to bias.

Several strategies are possible. First, one can examine the relationship between amphetamine-induced dopamine release and measures of social defeat in healthy individuals.

Second, it is likely that amphetamineinduced dopamine release is normally distributed and that the distribution in populations experiencing social defeat is shifted towards the right. Consequently, one could compare healthy individuals from a putative 'super-high-risk' group (e.g. second-generation Moroccans in The Netherlands) with natives. This type of research currently has limited feasibility because of the large numbers of individuals that would be required to demonstrate a small-to-medium-sized difference between groups.

Third, randomised studies of primates could be used to examine whether animals exposed to defeat stress develop greater dopamine activity than non-exposed animals.

Finally, history reveals natural experiments. During the period from 1984 to 1991, almost all Jews resident in Ethiopia migrated to Israel, where they are discriminated against primarily because of their Black skin colour. The hypothesis thus predicts that a comparative study on risks for ethnic subgroups within the Jewish population of Israel will find the highest risks for Ethiopian Jews.

In conclusion, we hope that the social defeat hypothesis proposed in this editorial will open new lines of enquiry into causal mechanisms in schizophrenia. The purpose of a hypothesis is not only to explain but to stimulate others to carry out empirical experiments to confirm or refute the proposal.

\section{REFERENCES}

Arseneault, L., Cannon, M., Witton, J., et al (2004) Causal association between cannabis and psychosis: examination of the evidence. British journal of Psychiatry, 184, $110-117$.

Boydell, J., van Os, J., McKenzie, K., et al (200I) Incidence of schizophrenia in ethnic minorities in London: ecological study into interactions with the environment. $B M J, 323,1-4$

Cantor-Graae, E. \& Selten, J. P. (2005) Schizophrenia and migration: a meta-analysis and review. American Journal of Psychiatry, 162, 12-24.

Covington, H. E. \& Miczek, K. A. (200I) Repeated social-defeat stress, cocaine or morphine. Effects on behavioral sensitization and intravenous cocaine selfadministration "binges". Psychopharmacology, $\mathbf{1 5 8}$, 388-398.

David, A. S., Malmberg, A., Brandt, L., et al (1997)

IQ and risk for schizophrenia: a population-based cohort study. Psychological Medicine, 27, I3II-1323.

Isovich, E., Engelmann, M., Landgraf, R., et al (2001) Social isolation after a single defeat reduces striatal dopamine transporter binding in rats. European Journal of Neuroscience, 13, 1254-1256.

Janssen, I., Hanssen, M., Bak, M., et al (2003) Discrimination and delusional ideation. British Journal of Psychiatry, 182, 7I-76.

Laruelle, M. (2003) Dopamine transmission in the schizophrenic brain. In Schizophrenia (eds S. R. Hirsch \& D.Weinberger), pp. 365-387. Oxford: Blackwell.

Pedersen, C. B. \& Mortensen, P. B. (200I) Evidence of a dose-response relationship between urbanicity during upbringing and schizophrenia risk. Archives of General Psychiatry, 58, 1039-1046.

Tidey, J.W. \& Miczek, K. A. (1996) Social defeat stress selectively alters mesocorticolimbic dopamine release: an in vivo microdialysis study. Brain Research, 72I, 140-149. 